\title{
A MULHER E A VIOLÊNCIA. UMA DEVASTAÇÃo SUBJETIVA
}

\author{
Women and Violence. A Subjective Devastation \\ La Mujer y la Violencia. Una Devastación Subjetiva \\ La Femme et la Violence. Una Desvastation Subjectif
}

\begin{abstract}
Resumo
A clínica com as mulheres que apresentam um intenso sofrimento psíquico em decorrência da submissão a reiteradas situações de violência doméstica e o número significativo de mulheres que se encontram nessa condição psicossocial coloca a necessidade de refletirmos sobre as condições de subjetivação dessas mulheres. Considerando o conceito freudiano de catástrofe e o conceito lacaniano de devastação para falar de uma relação intensa da filha com a mãe, proponho-me a examinar a ideia de que as mulheres em situação de violência apresentam um processo de destituição narcísica provocada por falência na possibilidade de estruturação de unidade imaginária, operada por uma relação com a mãe devastação que não lhe possibilitou a constituição de inscrição desejante. Desse modo, trata-se aqui de examinar as consequências que a relação mãe/homem, devastação produz para a constituição subjetiva dessas mulheres. Considero que a devastação operada na relação com a mãe é reeditado tragicamente em cada ato de agressão sofrida, colocando em cena a expressão de um gozo apartado da palavra. Essa situação leva, na minha análise à devastação subjetiva que se manifesta por desamparo e imensa falta de recursos para conseguir mudar de posição subjetiva, diante da emergência de um excesso que não consegue ser simbolizado.
\end{abstract}

Palavras-chave: violência; devastação; subjetividade; feminino; gozo.

\begin{abstract}
The clinic with women who have an intense psychological distress as a result of submission to repeated domestic violence situations and the significant number of women who find themselves in this psychosocial condition, puts the need to reflect on the conditions of subjectivity of these women. Considering the Freudian concept of disaster and the Lacanian concept of devastation to talk about an intense relationship between mother and daughter, I propose to examine the idea that women in situations of violence present a narcissistic destitution process caused by the bankruptcy of possibility when it comes to structuring imaginary unit, operated by a relationship with the mother, devastation didn't allowed her to constitute a desiring enrollment. Thus, this article aims to examine the consequences that the mother/man relation, devastation produces to the subjective constitution of these women. I believe the devastation wrought in the relationship with the mother is tragically redone in every act of aggression, which brings the expression of jouissance departed from the word. This situation leads, in my analysis to the subjective devastation that is manifested by dereliction and great lack of resources to achieve change in the subjective position, before the emergency of an excess that cannot be symbolized.
\end{abstract}

Keywords: violence; devastation; subjectivity; female; jouissance.

\section{Resumen}

La clínica de mujeres que tienen un sufrimiento psicológico intenso decurrente de la sumisión a situaciones de violencia doméstica y el número significativo de mujeres que

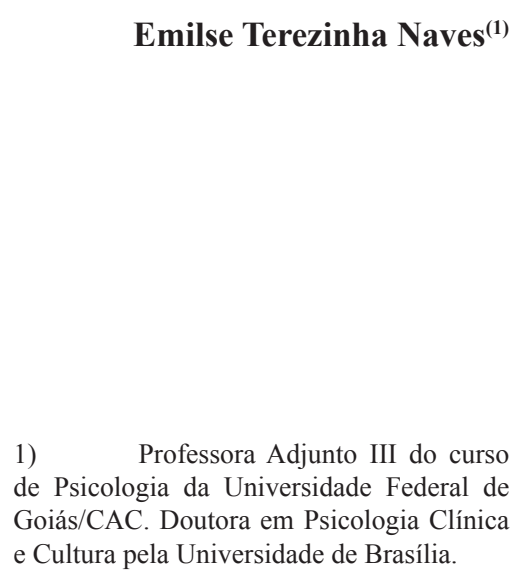

Recebido em: 22/04/2013

Revisado em: 11/04/2014

Aceito em: 14/10/2014 
se encuentran en esta condición psicosocial expresa la necesidad de reflexionar sobre las condiciones de la subjetivación de estas mujeres. En consideración al concepto de Freud de catástrofe y el concepto de Lacan de devastación para hablar de una relación intensa de hija y madre, me propongo examinar la idea de que las mujeres en situación de violencia tienen un proceso de destitución causado por la rotura de la posibilidad de estructuración de la unidad imaginaria causada por una relación con la madre, devastación que no le permitió la constitución de inscripción del deseo. Por lo tanto, se trata aquí de examinar las consecuencias que la madre/hombre, devastación produce para la constitución subjetiva de esas mujeres. Creo que la devastación causada de la relación con la madre trágicamente está reproducida en los actos de la agresión sufrida, poniendo en escena la expresión de un goce apartado de la palabra. Esta situación conduce, en mi análisis, a la devastación subjetiva manifestada por el abandono y la falta de recursos para alcanzar el cambio de la posición subjetiva frente a la emergencia.

Palabras clave: violencia; devastación; subjetividad; femenino; jouissance

\section{Résumé}

La clinique avec les femmes qui présentent un intensif souffrance psychique en décurrent de la soumission levée de situations de violence domestique et le numéro significatif de femmes que se trouve dans cette condition psychosocial, met la nécessité de nous réfléchir sur les conditions de subjetivation de ces femmes. En considerant le concept freudian de catastrophe et le concept lacanian de dévastation pour parler d'une relation intensive de la fille avec la mère je me propose à examiner l'idée que les femmes en situation de violence présentent un processus de destitution narcisique provoquée par l'echec de la possibilité de structuration de l'unité imaginaire, opérée par une relation avec la mère dévastation qui n'a lui pas rendu possible la constitution d'inscription souhaité. De cette façon, on discute ici l'acte d'examiner les conséquences que la relation mère/ homme, devastation produit pour la constitution subjective de ces femmes. Je considere que la devastation opérée dans la relation avec la mère est réédité tragiquement en chaque acte d'agression souffert, en mettant en scène l'expression d'un jouissance lointain du mot. Cette situation mène, dans mon analyse, à la devastation subjective que se manifeste par délaissement et un immense manque de recours pour réussir à changer de position subjective, devant l'émergence d'un excès qui n'arrive pas à être symbolisé.

Mots-clés: violence; devastation; subjectivité; féminin; jouissance.

Os principais textos freudianos sobre a feminilidade foram publicados após 1920, período em que Freud rege virada fundamental na compreensão do aparelho psíquico. A pulsão de morte passa a ser o lócus principal na orquestração dos diversos elementos conceituais presentes na constituição do psiquismo. Temas como feminilidade, pulsão de morte e o término de análise passam a ser examinados a partir desse período até suas últimas publicações. Uma análise mais atenta mostra que o interesse de Freud por tais temas não se restringe apenas a uma simples diversificação de interesse em relação a essas problemáticas, mas parece indicar uma sinalização sobre ligação particular entre essas temáticas.

A construção teórica freudiana sobre a feminilidade é alicerçada no primado do falo e numa concepção negativa dos embates com a falta desse. Nessa perspectiva a mulher é vista como castrada e representada no registro da falta, concepção centrada hegemonicamente no campo da diferença sexual e da linguagem. Não cabe aqui retomar o percurso freudiano sobre a teoria da feminilidade, mesmo porque essa teorização encontra-se bem fundamentada pela literatura psicanalítica. Interessa-nos em particular nesse estudo lançar a ideia de que o discurso freudiano não se esgota apenas nesse registro. Embora Freud não tenha objetivamente e diretamente se afastado de uma concepção estrita da sexualidade feminina a partir de um ponto de vista no qual exista apenas um significante, o falo, e das peripécias urdidas por homens e mulheres ou pela angústia em perdê-lo ou pelo desejo em possuí-lo, ele não deixou de apontar as descontinuidades, obscuridades e enigmas não apenas ao que tange a configuração psíquica da mulher, mas principalmente das lacunas presentes em sua teoria sobre a feminilidade.

Birman (2001), em seu estudo sobre o discurso freudiano acerca da feminilidade, faz contundente crítica à teoria de Freud que, segundo o autor apresenta um estatuto de negatividade, ficando atrelado às concepções da feminilidade de seu tempo. Ele propõe, porém, de forma muito consistente, outra vertente sobre a origem da teoria freudiana acerca da feminilidade, concebida após a introdução do conceito de pulsão de morte. Os estudos freudianos, após os anos 1920, possibilitam pensar a feminilidade em Psicanálise, a partir de registro positivo, no qual a feminilidade pode ser vista não como destino apenas, mas como origem e como elemento estruturante da subjetividade. A constituição da feminilidade pressupõe a perda do ideal fálico da perfeição e completude, reconhecendo no corpo das mulheres e em sua subjetividade a marca das hiâncias, da finitude e da imperfeição.

A ideia freudiana que concebe o masoquismo como originário, ainda nos lembra Birman (2001), seria a prova cabal do "reconhecimento flagrante, pela psicanálise, de que as intensidades, a força pulsional, a pulsão de morte e a afetação estariam na origem (p. 239). Assim, “a feminilidade seria enfim, um outro nome para denominar o masoquismo erógeno, maneira do sujeito lidar com as intensidades e com as forças pulsionais, sem se valer e precisar necessariamente do referencial fálico" (Birman, 2001, p. 240). A concepção da feminilidade proposta pelo autor a partir de uma releitura do último Freud é pertinente para pensarmos nos descaminhos e na impossibilidade de 
uma sublimação no universo de algumas mulheres, que não só não conseguem a assunção da feminilidade como condição subjetiva de aceder ao desejo, a erogeneidade e a criação, como se mantém prisioneiras no campo das intensidades, sem recursos para transformar o excesso pulsional em novas possibilidades de subjetivação.

As mulheres em situação de violência materializam, em suas relações e em suas condições de vida, um modo de construção subjetiva marcada por avassaladora passividade, na qual as condições psíquicas que permitem o domínio das forças pulsionais pelos processos de simbolização não são dadas, mantendo tais forças submetidas à intensidade traumática, desencadeando um processo que chamarei de devastação subjetiva. A problemática vivida por essas mulheres indica a presença de forças pulsionais que apontam para um gozo indizível, sendo que a violência representa não um sintoma interpretável, retorno do recalcado que merece ser decifrado, mas algo que resiste e insiste em não ser captado pelas malhas da linguagem. A presença insistente e a submissão a atos recorrentes de violência, como mostram as estatísticas, evidencia que as mulheres submetidas a essa condição de violência colocam em ato, acontecimentos traumáticos que não lhes possibilitaram a construção de seu nome próprio. Essa problemática apresentada pelas mulheres vítimas de violência aponta para condições primárias que não the permitiram realizar um desintrincamento pulsional, assumindo passivamente sua condição de assujeitamento frente a um real avassalador. Com isso, a cada vivência com seu companheiro em que um ato de violência ganha destaque, ela nos coloca diante da repetição, de uma forma de relação, marcada pelo não reconhecimento de sua condição de sujeito. A origem dessa posição subjetiva de manter-se enclausurada num devastador aniquilamento subjetivo pode estar relacionada a um impasse no desenvolvimento de uma relação primeira entre a menina e sua mãe que, ao invés de lhe garantir condições de inscrição na trama edípica e suas consequências para a constituição de sua feminilidade, lhe arrebata a uma posição de fixação numa relação organizada para além do desejo, sustentada pela emergência de um gozo que não se significa. E, justamente por não serem dadas condições de elaboração e simbolização que esse modo de relação se constitui em um núcleo traumático, não encontrando outra via de expressão senão na insistente repetição nas suas escolhas amorosas marcadas pela emergência da violência.

Com base nessas questões, esse estudo pretende problematizar o papel da compulsão à repetição e as origens primitivas na relação com a mãe como fator possível que determina a permanência da mulher numa condição de violência, dificultando a emergência dos processos de subjetivação. O objetivo principal desse estudo visa elucidar a questão que o conceito lacaniano de devastação ocupa nas posições subjetivas assumidas pelas mulheres em situação de violência Embora essas questões tenham como ponto de partida a clínica psicanalítica, será realizada uma pesquisa teórica, elegendo conceitos fundamentais da teoria freudiana e lacaniana que possibilitem a discussão da problemática apresentada.

\section{Bate-se em uma Mulher}

Os estudos sobre a problemática da mulher em situação de violência apresentam-se, nas mais diversas áreas do conhecimento, como um tema de grande interesse, sendo possível encontrar uma variedade de estudos científicos em diferentes abordagens teóricas e campos do saber. No entanto, apesar dessa multiplicidade de estudos, esse tema continua nos propondo uma série de enigmas que, ainda, estão longe de serem esgotados.

O estudo dessa problemática surgiu com base em atendimentos clínicos realizados na clínica-escola do curso de Psicologia da Universidade Federal de Goiás/ Regional Catalão. A prática clínica desenvolvida nessa instituição mostrou um número significativo ${ }^{1}$ de mulheres que procuram por atendimento psicológico em decorrência da presença de transtornos mentais ocasionados primariamente ou secundariamente pelo enfrentamento de situações de violência. Além da prevalência desses casos, constituindo-se num problema de saúde mental, verificamos também dificuldades de encontrar estratégias adequadas para minimizar o alto índice de interrupção dos trabalhos terapêuticos realizados com tais pacientes e, como consequência, a manutenção e recorrência da submissão aos atos de violência.

Trata-se, portanto, de um problema multifacetado, englobando questões históricas, sociais, políticas e culturais que traz graves prejuízos tanto para os sujeitos em situação de violência como para todas as instâncias sociais envolvidas no trabalho com a violência e, como consequência para a população em geral. Dessa forma, as questões emergentes na clínica atual e nas mais variadas instituições sociais nos confrontam incessantemente com as repercussões dos atos de violência cometidos contra a mulher.

Segundo pesquisa divulgada pelo Data Senado, em 2013, 700 mil brasileiras sofreram algum tipo de agressão, correspondendo a $19 \%$ da população feminina com mais de 16 anos. As estatísticas apontam índices alarmantes de violência contra a mulher, apesar dos avanços alcançados na promulgação de leis mais severas de proteção aos direitos

1 Verificamos que entre os anos de 2010 a 2013 em um universo de noventa mulheres, atendidas no Centro de Estudos Aplicados em Psicologia da Universidade Federal de Goiás/ Regional Catalão ,aproximadamente $10 \%$ mencionaram, no decorrer do processo psicoterápico, agressões verbais, físicas ou sexuais cometidas por seus companheiros. 
da mulher e das políticas públicas de cuidados a saúde física e mental das mulheres submetidas a uma situação de violência. Nesse sentido, segundo levantamento realizado pelo Data Senado (2013) entre 2005 e 2013, o índice de violência doméstica e familiar manteve-se no patamar de $18 \%$. Ainda assim, os números continuam preocupantes apontando um alto índice de conduta baseada no gênero, que causa morte, dano ou sofrimento físico, sexual ou psicológico à mulher. Em relação às taxas de homicídios femininos as estatísticas mostram que, entre 1980 e 2010, tiveram uma evolução na ordem $4,92 \%$, sendo que na última década 43,5 mil mulheres foram assassinadas no Brasil (Waiselfisz, 2012).

Embora existam diversas tentativas para explicar e trazer contribuições para a compreensão da violência doméstica, em diversas áreas do conhecimento, a realidade impõe uma repetição que escapa às várias tentativas de elucidar as causas no aumento dessa problemática, indicando que existe algo nesse contexto que não se inscreve.

A violência destitui o sujeito, ou seja, retira dele seu lugar de alguém que pensa, sente e deseja. A pessoa exposta à violência ocupa um lugar de passividade, de não poder falar, de estar assujeitada ao outro. A ideia de estar submetido ao outro, de ser humilhado e espancado, chamou atenção de Freud, que em 1919, estudou as fantasias primitivas de espancamento de crianças por meio do relato feito por seis pacientes, sendo quatro mulheres. Nesse estudo, Freud se interessou em esclarecer o papel desse tipo de fantasia na construção de um traço primário de perversão. Para Freud os aspectos sádicos e masoquistas dessas fantasias sofrem a ação de processos de defesa que impedem essas fantasias, que tem o objetivo de uma satisfação auto-erótica, sejam atuadas como perversões.

Existiria uma relação entre a construção dessas fantasias primitivas e o caso das mulheres vítimas de violência doméstica? Não se trata aqui de realizar um estudo exaustivo desse texto freudiano, de 1919, mas apontar que a análise de Freud direciona-se na perspectiva de uma construção fantasmática que tem como base o envolvimento da criança "nas agitações do seu complexo parental" (Freud, 1919/1987c, p. 233). Freud esclarece que a segunda fase da fantasia - estou sendo espancada pelo meu pai - a qual só pode ser compreendida a partir de uma construção clínica, pois jamais foi consciente - trata-se da substituição do desejo de ser espancado pelo pai pelo desejo de amor pelo pai. Ao mesmo tempo é uma fixação de amor à figura paterna e as condições de propagação de "rancor e rivalidade da menina em relação à mãe" (ibidem). No entanto, Freud esclarece que essa hostilidade pode também permanecer lado a lado com uma atitude de "excessiva dedicação à mãe" (ibidem). O que essa expressão quer dizer? Não podemos nos esquecer de que se trata aqui do registro de uma fantasia que sofreu a ação do recalque, permanecendo como um traço primário de uma perversão. Porém, quando este recalque falha a estruturação de um sintoma neurótico ou de uma perversão, esse traço se faz presente. Nesse contexto, poderíamos até considerar que as mulheres violentadas mantêm traços de uma fantasia primitiva da ordem que Freud nos apresenta, podendo nos levar a uma conclusão apressada que estaria na base de um registro masoquista. Mas não podemos deixar de considerar que a construção de uma fantasia inconsciente está relacionada com a questão do desejo e, como lembra Laplanche e Pontalis (1985, p. 232) "se encontra subjacente por detrás das produções do inconsciente como o sonho, o sintoma, o agir, os comportamentos repetitivos, etc".

A relação entre o masoquismo e a mulher em situação de violência, baseados numa discussão freudiana acerca da concepção do masoquismo feminino e das fórmulas de sexuação delineadas por Lacan, concebendo a violência doméstica como um sintoma seja da mulher seja do homem, tem sido objeto das pesquisas de vários autores de orientação psicanalítica sobre a violência contra a mulher. Por exemplo, Miranda e Ramos (2014), ao discutirem a parceria amorosa da mulher na condição de violência afirmam que ela:

Consente em ser objeto a causa de desejo, ao encarnar uma posição servil diante de seu parceiro cujo ápice reside em ser espancada por ele quase diariamente. Dessa forma, ela se aloja em seu fantasma como objeto de gozo dele. É ela, a mulher, mascarada com um masoquismo, que dá conta de localizar o gozo fálico do marido. (p. 46)

No entanto, essa leitura deve ser pensada com cuidado, pois atualmente vários conceitos e princípios freudianos, acerca do masoquismo e da mulher, têm sido problematizados e revisados (Narvaz, 2010). Nesse sentido, Soler (2005, p. 61) afirma que "os textos que Freud dedica ao masoquismo, preciosos em muitos aspectos, nada nos ensina sobre a mulher em si". Seguindo essa linha de pensamento, posso afirmar que não se trata de considerar a mulher que sofre violências como sendo masoquista.

Dentro dessa proposta de estudo, entendo que essa articulação entre fantasia, desejo e sintoma pode estar presente no funcionamento das mulheres que são repetidamente agredidas, principalmente se estiverem relacionados a algum quadro neurótico. Contudo, proponho que a presença implacável da compulsão à repetição, marcando a vida dessas mulheres e determinando um assujeitamento a essa situação, indica outro caminho que nos faz vislumbrar algo que ultrapassa a ordem do sintoma e da produção de fantasias masoquistas. Freud, desde os estudos sobre a histeria, concebe o sintoma como uma 
formação de compromisso entre o desejo inconsciente e os processos de defesa, indicando, portanto, que o sintoma busca uma interpretação, um sentido, estando associado a uma produção da linguagem. Não deixa de ser então, uma mensagem capaz de ser traduzida e quem sabe resolvida. Mas o próprio Freud chega à conclusão ao final de sua obra que as coisas não são assim tão simples. A compulsão a repetição, o irredutível mal-estar presente na sexualidade mostra que algo resiste em ser nominado (Brancion, 1996).

\section{Um Inexorável Mal-estar}

Uma das questões mais alarmantes, no que se refere à problemática das mulheres em situação de violência, diz respeito a uma adesividade implacável à manutenção na condição de violência. Na maioria dos casos, por mais que os sistemas jurídicos e de saúde tentem retirar essas mulheres dessa condição de assujeitamento, as estratégias de abordagem acabam fracassando. Essas mulheres permanecem sendo violentadas. Suas histórias de vida mostram violência recorrente. A experiência clínica mostra que, geralmente, as mães sofreram violência, repetindo depois essa mesma história quando da escolha de um companheiro, depois de outro e outro. Um destino inexorável? Não para a Psicanálise. Como lembra Freud, não se trata da perseguição de um "destino maligno", mas de uma repetição que foi orquestrada por elas mesmas e "determinado por influências infantis primitivas" (1920/1987d, p. 35).

Em Além do princípio de prazer (1920/1987d), Freud ao elaborar sua teoria sobre o fenômeno da compulsão à repetição, desenvolve a hipótese de sua ligação a algo que "sobrepuja o princípio de prazer". Assim, as eternas repetições estão também a serviço da pulsão de morte, embora elas não contradigam o princípio de prazer. Essa ideia de uma repetição a serviço de um gozo indizível nos abre a possibilidade de pensar a violência contra a mulher como impossibilidade de fazer barreira contra a emergência de um excesso inominável. Nesse sentido, a questão não pode ficar sujeita à configuração de um sintoma neurótico como abordamos acima ou como a manifestação de atuações masoquistas, trata-se, portanto, de uma versão do pior (Fingermann \& Mendes, 2005). Um pior que remete ao além do princípio de prazer formulado como um princípio de repetição.

As violências repetem-se em todos os aspectos de suas vidas. Começam devagar, como abdicar de um desejo para atender ao desejo do outro. Depois, submetem-se às palavras mal-ditas e em seguida seus corpos se colocam passivamente, mas não sem consentimento, disponível para a colocação em ato do pior. E nos piores dos casos, o limite chega a ser a morte literal. A mídia e as estatísticas não nos poupam de notícias de mulheres assassinadas por seus companheiros, depois de reiteradas situações de intensos maus-tratos.

Para além das culpas, das implicações na determinação da violência, da condição de vítima e das gratificações narcísicas, o que se revela é um despojamento de si mesma. Elas não conseguem amar, nem se divertir, nem estudar, nem cuidar dos filhos, nem pensar e nem mesmo falar. Não falam, mas dizem sobre um vazio subjetivo extremo, de um desamparo e de uma falta de reconhecimento pelo Outro. Em contrapartida, essa quase total desistência de si passa vertiginosamente a uma relação de avassalamento ao parceiro agressor. Elas deixam que eles apropriem-se dos seus desejos, dos seus sonhos, de suas vidas. Assim, viver na rasteira do outro torna o seu lema. Sabemos, o quanto é difícil manter essas mulheres em atendimento psicanalítico; quase não há demanda por uma clínica e quando há, o foco é o parceiro. Ele se aninha em suas mentes, tal qual um objeto persecutório. Perseguem-nas em suas análises. E quando o analista lhe possibilita entrever uma "outra coisa", desistem da análise, sustentando o que Freud nos alertou em $O$ Narcisismo: uma introdução, que elas preferem a cura pelo amor que a cura pela análise. Mesmo que seja um "amor" que as deixe na pior. E por que "entregar-se ao pior?" (Fingermann \& Dias, 2005). Retomo, nesse momento, uma pergunta feita pela psicanalista Eliane Schermann (2003) com base na definição do conceito lacaniano de devastação, situando-a no contexto da problemática que aqui discutimos. "Por que, para uma mulher, um homem pode ser pior que um sintoma, podendo até mesmo ser uma devastação?" (p. 194, grifo nosso). A resposta pode ser direta, mas não tão elucidativa. Porque esse homem lhe permite reencenar um inexorável mal-estar, que coloca em ato, um excesso que se tornou impossível de ser transformado em sintoma, deixando seus corpos marcados por um gozo devastador e que culmina num progressivo processo de perda subjetiva.

\section{Uma Mãe sem Desejo}

O homem que se apresenta como uma devastação para uma mulher ao submetê-la a situações de violência, nos remete a considerar nessa condição de escolha do objeto de amor a reedição de um traço das relações primitivas da filha com a mãe que se construíram como uma catástrofe nas palavras de Freud ou como devastação como afirma Lacan.

Desde os Três Ensaios sobre a teoria da sexualidade (1905/1987a), Freud já se deparava com a importância do papel da mãe no desenvolvimento da sexualidade da mulher. No entanto, essa questão só foi realmente posta em evidência muitos anos depois no artigo denominado "Sexualidade feminina" (1931/1987f). Até 1931 Freud centrou seu interesse no estudo da feminilidade em relação 
ao vínculo estabelecido entre a menina e seu pai e suas consequências para a determinação do complexo de Édipo. A constituição da feminilidade se baseia nos embates da identificação fálica e da inveja do pênis. No texto de 1931, Freud desenvolveu estudos acerca da extensa ligação da menina com a mãe, o chamado pré-Edipo feminino. Essa questão já tinha sido apontada antes - $A$ psicogênese de um caso de homossexualismo numa mulher (1920/1987e) -, mas é a partir dessa data que Freud elabora o impacto da relação com a mãe para a construção da feminilidade. A complexa relação pré-edípica da menina com sua mãe se mantém mesmo depois de passar para a fase edípica. A relação com o pai é determinada pelas consequências da relação primária com a mãe, não desaparecendo, nem tampouco substituindo, a relação materna por completo.

Freud lembra que, sob o efeito das ameaças de castração, a menina renuncia à masturbação clitoridiana e se desvia de seu falicismo e, ao mesmo tempo, troca de objeto, o que lhe permite entrar na fase edípica. Por um lado, a menina precisa abandonar a mãe, objeto inicial de seu desejo fálico. Assim, começa por odiá-la e se torna hostil a essa mãe. No entanto, apesar desse ódio, ela deve conservá-la como objeto de identificação. A menina só conseguirá se tornar um sujeito feminino se, porventura, conseguir o feito de, ao mesmo tempo, separar-se dela e conservar traços identificatórios que a levarão ao encontro do pai. No entanto, o encontro com o pai é também problemático, pois a menina privada do falo revela uma falta na qual a figura paterna não pode, contudo, recobrir inteiramente. A menina estará sempre se confrontando com uma falta de representação que a mãe, como mulher, não pode lhe fornecer. Por outro lado, o pai apenas parcialmente se apresenta como uma referência simbólica, na medida em que a relação com a mãe não é definitivamente abandonada. Nesse sentido, Freud (1931/1987f) chama de "catástrofe" a relação duradoura com a mãe, uma ligação arcaica marcada por uma dependência que se faz por uma demanda de exclusividade recíproca, duplicada por uma violenta hostilidade e pela angústia de ser devorada pela mãe.

Lacan, por sua vez, entende essa condição de confronto entre mãe e filha como uma devastação. Assim, no texto $O$ Aturdito, de 1972, o autor afirma que

a elucubração freudiana do complexo de Édipo, que faz da mulher peixe na água, pela castração ser nela ponto de partida, contrasta dolorosamente com a realidade de devastação que constitui, na mulher, em sua maioria, a relação com a mãe, de quem como mulher, ela realmente parece esperar mais substância que do pai - o que não combina com ele ser segundo, nessa devastação. (Lacan, 2003, p. 465)
Em outros momentos de seus estudos, Lacan se referiu à devastação sempre mostrando que ela aponta para um estrago na relação mãe e filha que pode levar o sujeito a uma "abolição" subjetiva, ao mesmo tempo em que o colocaria em posição de se deparar com o Outro absoluto (Campanário, 2008).

A questão da devastação põe em evidência a leitura lacaniana da configuração feminina entre dois gozos, realizada a partir de 1972 em seu seminário Mais, Ainda, um pertinente ao registro do falo regido pela metáfora paterna e o outro no além do falo que denota a presença de um gozo não simbolizável. A mulher, por sua condição inexorável de confronto com o signo da falta (a ter e a ser), traz-lhe como consequência não poder encontrar um significante que a represente totalmente. Essa operação de não ser submetida completamente como o menino à metáfora paterna, por não ter um significante feminino que a represente, como o falo no caso do menino, está na base da condição de estruturação da mulher em sua condição de sexo feminino e na condição de sujeito. Nesse sentido, Soler (2005) afirmou que a utilização desse termo por Lacan vai "muito além das discórdias rivalizantes que são próprias do registro fálico" (p. 96) por significar uma desconstrução de "todos os referenciais".

A mãe, que se constitui como uma devastação para filha, não foi capaz de imprimir-lhe um revestimento imaginário suficiente para ser apenas um objeto de fantasia do desejo materno, regulado pela função simbólica. A mãe, incapaz de dar à filha um significante da falta, a aliena em uma relação que não abre espaço para a vivência da perda e da separação, necessária para a constituição de seu próprio desejo e de sua condição de sujeito. A filha torna-se, então, não objeto causa de desejo a partir do olhar materno, mas apenas objeto de gozo. Manter-se submetida a essa posição de objeto de gozo é, lembra Zalcberg. (2003), particularmente devastador para a menina, já que ela, "por estrutura, tem mais proximidade com o real" (p. 132). Ainda ressalta Zalcberg (2003), na mesma obra, sobre essa condição de objeto de gozo, que a filha na "relação com o homem ocupa a posição que corresponde ao lugar que ele lhe destina em sua fantasia: o lugar do objeto (a), causa do seu desejo" (p. 132). Permanecer refém desse lugar de responder permanentemente à demanda do Outro, como única possibilidade de sustentar uma referência identificatória, significa que, primordialmente, não foi também possível se sustentar no lugar de objeto de desejo da mãe. Para algumas mulheres, não ter tido a possibilidade de estabelecer uma relação materna na qual se instala o significante do desejo pode levá-las a um único caminho: o confronto permanente com o Outro real sem limite, que será insistentemente reeditado na relação com o homem que se torna devastação. Essa configuração é particularmente percebida na clínica 
com mulheres em situação de violência doméstica². Elas relatam em suas histórias de vida tanto a figura de uma mãe persecutória que não deixou de praticar atos de maus-tratos, abandonos e omissões como uma mãe devoradora que convoca a uma relação fusional mortificante. Em ambos os casos, a figura paterna é apresentada como impotente e incapaz de fazer barreira ao imperativo materno.

\section{Você É Apenas Isso}

A relação entre a mãe e a filha que se institui sob o significante da devastação produz consequências catastróficas para a constituição subjetiva das mulheres. Considerando que a devastação não deixa de ser uma forma de expressar a presença de gozo absoluto ao se "esbarrar no limite fantasmático" (Schermann, 2003), fica assim, impossível não ceder a uma desamarração pulsional. Diante disso, quais seriam os desdobramentos para os processos de subjetivação desse sujeito feminino? Esse fenômeno convoca a uma reflexão complexa, mas por ora, quero chamar a atenção para três aspectos principais que são visíveis na clínica com mulheres em situação de violência. O primeiro aspecto diz sobre a emergência de um corpo marcado por uma excitação pulsional indizível, revelada por uma experiência traumática. É principalmente ataque sobre o corpo que expõe a gravidade da violência sofrida, um corpo marcado por traumas, cortes, cicatrizes, indicando a presença de uma intensidade pulsional que resiste a uma inscrição desejante.

A instituição de um supereu tirânico e implacável é outro aspecto que encontramos na configuração psíquica das mulheres que sofrem violência. Elas manifestam todas as figurações desse supereu feroz, culpas com um caráter devastador, sacrifícios e renúncias sem limites, um estado melancólico crônico e quando em análise costumam desenvolver uma "reação terapêutica negativa". Não pretendo discutir esse aspecto, mas apenas apontar que a leitura dos estudos freudianos sobre a feminilidade, indica que a constituição do supereu feminino como herdeiro do complexo de Édipo, que se organiza de forma frágil pelo fato de a menina não se render completamente ao complexo de castração. Porém, Freud (1937/1987g) sugere em Análise terminável e interminável outra abordagem que mostra a configuração de um supereu arcaico materno, que poderia indicar sua face intransigente e cruel. Contudo, são os pós-freudianos que vão considerar mais abertamente essa questão, como Melanie Klein, Ferenczi e Lacan. No seminário As formações do inconsciente, Lacan pergunta: "Não haverá na neurose, por traz do supereu paterno, um supereu materno ainda mais exigente, mais opressivo, 2 Refiro-me aqui à clínica realizada no Centro de Estudos Aplicados em Psicologia do curso de Psicologia da Universidade Federal de Goiás/Regional Catalão. mais devastador, mais insistente?" (1999, p. 167). Nessa perspectiva, Lacan indica a concepção de um supereu que resulta de uma herança arcaica materna onipotente que leva a um imperativo do gozo marcando o fracasso do processo de simbolização.

Nesse momento, retomando a condição subjetiva na qual se instala a mulher em situação de violência, trago uma questão apontada por Didier-Weill (1997), que me parece bastante pertinente para o estudo em questão. A que posição subjetiva será remetido o sujeito que não pode responder sim ao mandamento simbólico lhe dizendo: "Lá onde isso era, se torne fala", uma vez que não pode responder não ao mandamento superegoico ao dizer: "Não se torne?" (p. 35), pergunta o autor? Para sustentar a resposta a esse questionamento, o psicanalista remete a "história do louco e da galinha", um louco que se toma por um grão de trigo e, quando recebe alta do hospital, recua ao se deparar com uma galinha porque não pode confiar que ela não saiba que ele não seja um simples grão de trigo. Esse joke, segundo o autor, é interessante, pois apresenta elementos que se assemelha ao que pode ser observado em algumas situações clínicas, aquelas em que o sujeito se vê impossibilitado em afirmar: "não, não sou apenas isso, não sou apenas um grão de trigo" (p. 36), sucumbindo a um Outro que, encarnando um superego arcaico insiste em lhe dizer: "Você é apenas isso, um grão de trigo" (p. 36).

Essa questão formulada por Didier-Weill chama a atenção para o fato de um sujeito não poder se posicionar e nem mesmo contestar frente a um imperativo superegoico absoluto, que the imprime a "palavra de ordem": "Nem uma palavra" (p. 35). A situação clínica das mulheres que sofrem violência nos remete, de modo tão pertinente, ao destino desse sujeito apontado pelo autor. Sabemos como essas mulheres se submetem ao jugo de seus agressores que, de certo modo, encarnam a voz desse supereu absoluto que lhe sentencia sua decadência e sua impossibilidade de o contradizer. A relação com o agressor se sustenta numa alienação primordial que coloca em cena o "jugo de uma maldição silenciosa" (p. 35), à qual se entrega de modo tão avassalador.

Os estudos sobre violência e gênero apontam para uma imposição silenciosa sobre os atos de violência tanto por parte da sociedade como da própria mulher na condição de violência ${ }^{3}$. As dificuldades que muitas mulheres têm em denunciar seus agressores e, quando ainda conseguem, desistem da denúncia, revela a subordinação e obediência, à proibição da palavra. Vemos, assim, o aniquilamento da palavra diante desse superego primordial encarnado pela mãe, devastação que não lhe possibilitou outro caminho que

3 Sobre esses estudos consultar o trabalho de FUKS, L.B. Violência e gênero, in Interlocuções sobre o feminino na clínica, na teoria, na cultura. São Paulo: Escuta. 
o de se confrontar com um gozo indizível. Um gozo que é atuado em cada corpo agredido, em cada palavra mal-dita, em cada palavra silenciada, e numa última possibilidade, em cada vida perdida.

\section{Devastação Subjetiva}

Mais uma vez perguntamos: diante desse gozo ilimitado, apartado de Eros, que não pôde se transformar em sintoma, resultante de uma relação de devastação, primordialmente com a mãe e secundariamente na relação com o homem, que posição subjetiva ocupa a mulher quando sofre reiterados atos de violência? Segundo Marie-Helène Brousse (2004), numa relação de devastação

o sujeito é despossuído de seu lugar. Esse lugar que não existe mais pode ser declinado como fala, o sujeito sendo então reduzido ao 'silêncio'; como corpo, o sujeito não passa de um 'corpo em excesso', ou uma carne desfalicizada que é um 'buraco negro'; como errância, fenômeno de despersonalização, de auto-eliminação. (p. 65)

As histórias clínicas das mulheres que se colocam numa posição de submissão frente à agressão pelo parceiro mostram que seu corpo se coloca apenas como objeto de gozo do Outro, seja sexualmente ou como objeto de agressões. Não foi possível encontrar um pai que lhes assegurasse um lugar fora de um gozo excessivo da mãe. Nessa condição, não the foi assegurada, pela mãe, a possibilidade de se reconhecer como um corpo desejante. Winnicott (1975) nos lembra que o rosto da mãe serve como espelho para que possa dar a criança um sentimento de "continuidade pessoal de existência". Não sendo possível ter uma resposta desse olhar, ou seja, quando a mãe não consegue devolver esse olhar dando-lhe um assentimento de existência de um corpo representado, resta-lhe, na maioria dos casos, o encontro com um corpo perturbado e marcado pelo excesso. Uma paciente há vários anos em situação de violência doméstica faz questão de mostrar ao seu analista as marcas da agressão sofrida. Ela diz: "Veja meu corpo, é puro hematoma". Essa afirmação parece demonstrar um paradoxo, pois ao mesmo tempo em que seu corpo marcado mostra algo que não pode ser significado, ela faz um apelo ao procurar no olhar do analista uma tentativa de resgatar o desejo do Outro, de cativar seu olhar.

No entanto, mulheres como a paciente citada embora façam tentativas de barrar a emergência desse excesso, mostram a existência do corpo como um lugar que contém um excesso em que as agressões sofridas superam sua capacidade de reação, se apresentando como um alvo passivo assujeitado ao gozo do Outro. Nesse contexto, o ataque ao corpo não deixa de significar também um ataque ao eu. Encontramos nesses casos uma falha na identificação imaginária, determinada pela dificuldade da mãe em lhe proporcionar as condições necessárias para a constituição de uma imagem integrada de si mesmo. A relação de devastação que essas mulheres tiveram com suas mães não lhes possibilitou encontrar no olhar da mãe o reconhecimento fundamental para a constituição da imagem total do próprio corpo e como condição da estruturação do eu. Vejo que é nesse sentido que a paciente tenta de alguma forma elaborar a negação desse olhar materno pelo apelo do olhar do analista ao seu corpo agredido.

A questão de uma falha na identificação imaginária nos remete a uma falha narcísica que provoca uma deflação do eu não sendo, portanto, capaz de impedir o aparecimento de um real dessexualizado. Com base na falta de Outro que possa balizar sua condição de sujeito, a relação com o outro só poderá se estabelecer numa condição de servidão. A condição de submissão assumida pela mulher na relação com o parceiro agressor nos parece revelar o que Freud (1914/1987b) propõe a partir do modelo do estado de uma pessoa apaixonada, no qual se observa um "empobrecimento do ego em relação à libido em favor do objeto amoroso" (p. 105). Nesse sentido, a falta do Outro leva a uma busca incessante pela onipresença do outro como uma forma de fazer valer sua posição insustentável de sujeito. Elas se colocam a disposição do outro, dando tudo sem moderação e sem reserva, muitas vezes em uma posição de sacrifício. Não medem as consequências numa tentativa desesperada de reparar a falta desse objeto, demandando um esforço incondicional na tentativa de torná-lo melhor, de modificálo. Não tornando possível essa missão, submergem em um sentimento de culpa avassalador, advinda de uma exigência imperativa de um supereu tirânico. Além disso, apresentam uma inibição do eu que se expressa numa incapacidade de administrar a própria vida. Vemos assim, a presença de um eu deflacionado resultado de um processo de destituição narcísica provocada por uma falência na possibilidade de constituição de uma unidade imaginária, desencadeando, desse modo, a experiência de um corpo tomado pelas forças pulsionais, que é vivenciado tragicamente em cada agressão sofrida. É assim, que para a mulher que sofre recorrentemente violências, o desejo passa a ser vivido como pura expressão da pulsão, o que faz com que ela seja capturada por um desamparo e uma imensa falta de recursos para conseguir mudar de posição subjetiva diante da manifestação do pior.

Em cada corpo violentado, em cada palavra silenciada, o que se coloca em cena é a emergência de uma devastação subjetiva provocada por uma primeira relação na qual o que se manteve como marca primordial foi a inscrição de um gozo sem nome. Um gozo que insiste em se fazer presente 
como atestam tragicamente as estatísticas. No entanto, essa realidade pode ser diferente caso seja dada condições a essas mulheres de, nas palavras de Brousse (2004, p. 67), "uma chance de inventar para si um nome" que elas "não tem para delimitar a zona de real nos confins da fala". Embora lhes tenha sido negada a via do desejo, é apenas pela via da construção fantasmática delimitada pela fala que poderão ter a chance de se inscrever em outra posição subjetiva.

\section{Referências}

Birman, J. (2001). Gramáticas do erotismo: A feminilidade $e$ as suas formas de subjetivação em psicanálise. Rio de Janeiro: Civilização Brasileira.

Brancion, M. M. C. (1996). Haverá um irredutível do sintoma? In Letra Freudiana, Do Sintoma ao Sinthoma (Ano XV- n. 17/18) (pp. 168-175). Rio de Janeiro: Revinter.

Brasil, Secretaria de Políticas para as Mulheres (2013). Violência contra as mulheres. Recuperado de www.spm. gov.br/assuntos/violencia/pesquisas-e-publicacoes/ pesquisas-e-publicacoes

Brousse, M.-H. (2004). Uma dificuldade na análise das mulheres. In J.-A Miller (Org.), Ornicar? De Jacques Lacan a Lewis Carroll (pp. 57-67). Rio de Janeiro: Jorge Zahar.

Campanário, I. S. (2008). Os efeitos da devastação na relação mãe-filha em um caso de risco de autismo. Reverso, 30(55), 47-52. Recuperado de http://pepsic. bvsalud.org/pdf/reverso/v30n55/v30n55a04.pdf

Didier-Weill, A. (1997). Os três tempos da lei: o mandamento siderante, a injunção do supereu e a invocação musical. Rio de Janeiro: Jorge Zahar.

Fingermann, D., \& Dias, M. M. (2005). Por causa do pior. São Paulo: Iluminuras.

Freud, S. (1987a). Três ensaios sobre a teoria da sexualidade. In Edição Standard Brasileira das Obras Psicológicas Completas de Sigmund Freud (Vol. 7). Rio de Janeiro: Imago. (Originalmente publicado em 1905)

Freud, S.(1987b). Sobre o narcisismo: uma introdução. In Edição Standard Brasileira das Obras Psicológicas Completas de Sigmund Freud (Vol. 12). Rio de Janeiro: Imago. (Originalmente publicado em 1914)

Freud, S. (1987c). Uma criança é espancada: uma contribuição ao estudo da origem das perversões sexuais. In Edição Standard Brasileira das Obras Psicológicas completas de Sigmund Freud (Vol. 17). Rio de Janeiro: Imago. (Originalmente publicado em

\section{9)}

Freud, S. (1987d). Além do princípio de prazer. In Edição Standard Brasileira das Obras Psicológicas Completas de Sigmund Freud (Vol. 18). Rio de Janeiro: Imago. (Originalmente publicado em 1920)

Freud, S. (1987e). A psicogênese de um caso de homossexualismo numa mulher. In Edição Standard Brasileira das Obras Psicológicas Completas de Sigmund Freud (Vol. 18). Rio de Janeiro: Imago. (Originalmente publicado em 1920)

Freud, S. (1987f). Sexualidade feminina. In Edição Standard Brasileira das Obras Psicológicas completas de Sigmund Freud (Vol. 21). Rio de Janeiro: Imago. (Originalmente publicado em 1931)

Freud, S. (1987g). Análise terminável e interminável. In Edição Standard Brasileira das Obras Psicológicas completas de Sigmund Freud (Vol. 23). Rio de Janeiro: Imago. (Originalmente publicado em 1937)

Fuks, L.B. Violência e gênero. In S. L. Alonso, D. M. Breyton, \& H. M. Albuquerque (Orgs.), Interlocuções sobre o feminino na clínica, na teoria, na cultura (pp. 302-310). São Paulo: Escuta

Lacan, J. (1985). O Seminário, Livro XX: Mais, Ainda. Rio de Janeiro: Jorge Zahar Editor. (Originalmente publicado em 1975)

Lacan, J. (1999). O Seminário, Livro $V$ : As formações do inconsciente. Rio de Janeiro: Jorge Zahar Editor. (Originalmente publicado em 1998)

Lacan, J. (2003). O Aturdito. In Outros escritos. Rio de Janeiro: Jorge Zahar Editor. (Originalmente publicado em 2001)

Laplanche, J., \& Pontalis, J. B. (1985). Vocabulário de psicanálise. São Paulo: Livraria Martins Fontes.

Miranda, C. E. S., \& Ramos, J. S. (2014). "Uma mulher é espancada": A violência doméstica contra mulher a luz da psicanálise. Ecos - Estudos Contemporâneos da Subjetividade, 4(1), 35-49. Recuperado de www.uff.br/ periodicoshumanas/index.php.

Narvaz, M. G. (2010). Masoquismo feminino e violência doméstica: Reflexões para a clínica e para o ensino de Psicologia. Psicologia Ensino \& Formação, 1(2). Recuperado de www.pepsic.bvsalud.org.

Schermann, E. Z. (2003). O gozo en-cena: Sobre o masoquismo e a mulher. São Paulo: Escuta.

Soler, C. (2005). O que Lacan dizia das mulheres. Rio de Janeiro: Jorge Zahar. 
Waiselfisz, J.J (2012). Mapa da Violência. Atualização: Homicídio de Mulheres no Brasil. Recuperado de http://mapadaviolencia.org.br/pdf2012/ MapaViolencia2012_atual_mulheres.pdf. Acesso 20/09/2013.

\section{Endereço para correspondência:}

\section{Emilse Terezinha Naves}

Endereço: Rua João Luiz, 111, casa 11, Bairro São José.

CEP: 75.702-531, Catalão - GO.

E-mail: emilsenaves@yahoo.com.br 